\title{
A Case of Genital Tuberculosis Presenting as HSIL on Cervical Biopsy
}

\author{
Apra Attri ${ }^{1}$, Priyanka Sharma ${ }^{1}$, Sita Thakur $^{2}$, Ashok Verma $^{2}$, Kamal Singh $^{3}$ \\ ${ }^{1}$ Junior Resident, Dr. RPGMC, Kangra, HP, India \\ ${ }^{2}$ Professor, Department of Obstetrics and Gynaecology, Rajendra Prasad Government Medical College, Kangra \\ at Tanda, HP, India \\ ${ }^{3}$ Consultant, Department of Obstetrics and Gynaecology, Rajendra Prasad Government Medical College, \\ Kangra at Tanda, HP, India \\ Corresponding Author: Priyanka Sharma
}

\begin{abstract}
Genital tuberculosis is a frequent cause of chronic PID and infertility. Cervical TB is rare in postmenopausal women. We present a case of a post menopausal patient, who presented with a complaint of blood mixed discharge per vaginum for six months. Her preliminary investigations were consistent with that of HSIL/ High grade cervical dysplasia. Upon further evaluation, histopathological examination confirmed the possibility of tuberculosis instead.
\end{abstract}

Keywords: HSIL, Genital tuberculosis, Cervical biopsy

\section{INTRODUCTION}

In developing countries like India, Genital tuberculosis has a higher rate of prevalence, and it affects people mostly in the reproductive age group ${ }^{[1][2]}$. It is a frequent cause of chronic PID and infertility ${ }^{[3]}$. It has been estimated that $5-15 \%$ of cases of pulmonary $\mathrm{TB}$ develop genital tract infection ${ }^{[4]}$. Genital tuberculosis affects the fallopian tubes (95-100\% of the cases), the endometrium (50-60\% cases), and the ovaries (20-30\% cases). Of all the cases of TB, Cervical TB accounts for $0.1-0.65 \%$ and $5-24 \%$ of genital TB cases, thus it is extremely rare ${ }^{[1]}$. It is more common in women whose age is less than 40 , and rarely presents in postmenopausal ${ }^{[5]}$.

\section{CASE REPORT}

We report a case of 59 year old postmenopausal P1001 presented to the OPD with complaint of blood mixed discharge per vaginum for six months. Her perabdomen examination was within normal limits. On per-speculum examination of the patient, her cervix was pulled up, which bled on touch and was flushed with vagina. On per-vaginum examination, Uterus was retroverted, normal size with cervical os deviated to left.

On ultrasonography, her endometrial thickness was found to be increased upto $10 \mathrm{~mm}$. She was advised pap smear for suspicious cervix. An endometrial biopsy was also recommended for increased ET.

Pap smear report revealed many giant cells with occasional granulomas.

Endometrial biopsy showed endometrial tissue with scattered Langhans Giant cells in the stroma and endometrial glands in early secretory phase. There were epithelial macrophages, lymphocytes, plasma cells and occasional granulomas suggesting possibility of non-necrotizing granulomatous endometritis.

Cervical biopsy under colposcopic guidance was carried out and it revealed ectocervical tissue with high grade dysplasia. 
ZN stains of the same slides were non contributory to the diagnosis.

Endometrial biopsy culture for AFB was negative.

Her chest X-RAY was within normal limits and showed no evidence of pulmonary tuberculosis.

Since the patient belonged to a rural area and could not be followed up, she was scheduled for $\mathrm{TAH}+\mathrm{BSO}$ for high grade cervical dysplasia. Intra-operatively there were no adhesions, lymph nodes, ascitic fluid. Uterus was menopausal size, grossly normal. The $\mathrm{B} / \mathrm{L}$ tubes and ovaries were also grossly normal.

The specimen was sent for histopathological examination, the reports of which revealed that the endometrium showed epithelioid cell granuloma with giant cells, indicating possibility of tuberculosis. The cervix showed squamous metaplasia (L-SIL). Both adnexae were unremarkable.

Based on her reports, she is now started on ATT for extrapulmonary tuberculosis and advised regular 3 monthly follow up vault PAP smear.

\section{DISCUSSION}

Papanicolaou smears have proven to be an immensely important tool in the diagnosis of preneoplastic and neoplastic lesions of the cervix. However, its role in inflammatory conditions is relatively limited especially in diseases affecting the deeper part of the cervical stroma. Cervical tuberculosis is one such disease, the detection of which by cervical smears is ever rarer.

In genital tuberculosis, the organs are infected by a haematological spread from a primary focus. Cervical TB often occurs secondary to tuberculous salpingitis and endometritis. Cervical TB as a primary infection from an infected partner is rare. In females, Genital TB often presents with amenorrhoea, menstrual irregularities, infertility, vaginal discharges and postmenopausal bleeding ${ }^{[1]}$.
Cytology, histology and bacteriology are used to establish the diagnosis of genital TB. Pap smear can offer provisional diagnosis while EB is one of the simplest diagnostic methods. When culture is negative, aetiologies of granulomas like lymphogranuloma venereum, sarcoidosis and schistosomiasis must be undertaken ${ }^{[5]}$.

Granulomatous inflammation of the cervix and uterine corpus is rare, and it not typically associated with constitutional symptoms. It is usually detected during a local gynaecological examination [6] Tuberculous granulomas are commonly localized to mucosa, and in $20 \%$ of the cases the myometrium is affected.

\section{CONCLUSION}

Carcinoma cervix is more common than TB cervix. Induration of tuberculous cervicitis, which accompanies ulceroproliferative growth, can be mistaken for malignancy in clinical settings. For proper management of this non-neoplastic condition, and its accurate diagnosis, these cases must be evaluated carefully, especially in developing countries where $\mathrm{TB}$ is epidemic.

\section{Acknowledgement: None}

\section{Conflict of Interest: None}

\section{Source of Funding: None}

\section{REFERENCES}

1. Sabita S., Sharmila V., Arun T., Sinhasan S., Darendra S, "A rare case of cervical tuberculosis which stimulated carcinoma of the cervix," Journal of Clinical and diagnostic research, vol 7(6): 1189-90, 2013.

2. Samantaray S., Parida G., Rout N., Giri S., Kar R., "Cytological detection of TB cervicitis," Acta cytologica 2009; 53: 594-6.

3. Kaur T., Dhawan S., Aggarwal A., Bansal S., "Vulval Tuberculosis," J Obstet Gynaecol India. 2012 Aug; 62(4): 450-451. 
4. Gupta R., Dey P., Jain V. and Gupta N., "Cervical tuberculosis detection in Papanicolaou-stained smear: case report with review of literature," Diagnostic Cytopathology, vol. 37, no. 8: 592-5, 2009

5. Lim P., Atan I., Naidu A., "Genitourinary tuberculosis: an atypical clinical presentation," Case reports in Obstetrics and gynecology, 2012.

6. Mohammad O., Laurence E., Prysak M., Johnson L., Khatib R., "Utherine granulomas: clinical and pathological features," Am J Clin Pathol 2002; 117:771-5.

How to cite this article: Attri A, Sharma P, Thakur $S$ et.al. A case of genital tuberculosis presenting as HSIL on cervical biopsy. Int J Health Sci Res. 2021; 11(7): 168-170. DOI: https://doi.org/10.52403/ ijhsr.20210724 